\title{
Administration of electroconvulsive therapy: training, practice and attitudes
}

\author{
Tom Henderson, Senior House Officer in Psychiatry, Leverndale Hospital, Crookston \\ Road, Glasgow G53; MARILYN J. ANDERson, Community Psychiatric Nurse, \\ Southern General Hospital, Govan Road, Glasgow G51; and Cameron R. Stark, \\ Registrar, Department of Public Health, Ross House, Hawkhead Road, \\ Paisley PA2 7BN
}

Electroconvulsive therapy (ECT) is an effective treatment in severe depressive illness (Kendell, 1981). It is unusual in being administered predominantly by junior doctors, although prescribed by consultants. Pippard (1988) has drawn attention to a tendency for practice to depend on established custom rather than research evidence, and to a lack of consultant involvement in ECT teaching.

The Royal College of Psychiatrists published guidelines on the practical administration of ECT in 1989, and Pippard audited administration of ECT in 1991, producing a series of recommendations (Pippard, 1992). This study, designed in the light of Pippard's recommendations and the College guidelines, investigated the training given to doctors administering ECT, gathered information on their routine practice, and inquired into their own attitudes and those encountered in others.

\section{The study}

Complete lists of junior doctors working in psychiatry were obtained for the hospitals sending doctors to the West of Scotland Psychiatric Day Release Programme. A further seven individuals at these hospitals, staff grade doctors, associate specialists or clinical assistants who administered ECT, were identified by informal discussion. Selfcompletion questionnaires were sent to the 115 doctors identified, accompanied by a covering letter. A reply-paid envelope was enclosed.

Reminders and repeat questionnaires were sent to non-responders three weeks later. Responses were collated and analysed using Epi Info 5, a computer software program.

\section{Findings}

Eighty-seven doctors replied (76\%). They included 57 psychiatric trainees (66\%), 23 general practice vocational trainees $(26 \%)$ and six others $(7 \%)$. Respondents had spent a median of 23 months in psychiatry (range 3-240 months). Eighty-six (99\%) had administered ECT, although eight were not responsible for the practical administration of ECT during their current placement. The following results exclude the one doctor who had not administered ECT. Not all respondents answered every question.

\section{Training}

Doctors were asked what training they had received in the theory of ECT. They could indicate more than one option, and so totals are over $100 \%$. Thirty-four $(40 \%)$ had attended a postgraduate lecture; $42(49 \%)$ a postgraduate seminar; $40(47 \%)$ had received teaching at an ECT session and $42(49 \%)$ reported informal teaching. Six (7\%) stated that they had received no teaching. Asked about teaching in the practical administration of ECT, $68(79 \%)$ had received teaching in an ECT session; $15(17 \%)$ in a postgraduate lecture; $43(50 \%)$ in a postgraduate seminar, and six $(7 \%)$ had been shown a video. Five $(6 \%)$ recalled no teaching.

Fifty-four (63\%) doctors had been issued with written guidelines on the practical administration of ECT. Doctors were asked whether a consultant had been present while they administered ECT, other than at an introductory session. Thirteen (15\%) reported that a consultant had been present on at least one occasion, while $73(85 \%)$ could not recall a session attended by a consultant.

\section{Practical administration}

Eight (9\%) administered ECT weekly; 47 (55\%) every two to four weeks and $23(27 \%)$ every five to 12 weeks. Doctors were asked whether seizures were timed and, if so, what method was used. Two doctors did not time seizures; $63(73 \%)$ timed seizures with an ordinary clock or wristwatch and $21(24 \%)$ used a stopwatch or stopclock. Sixty-two (72\%) respondents used a minimal stimulus (the lowest which would produce an acceptable seizure); 10 (12\%) a fixed stimulus (classified as replies such as "always the same stimulus", and "set by the nurses"), and 12 
(14\%) reported using an intermediate stimulus (greater than that required to produce a seizure, but less than the maximum possible). Two gave no response to this question.

Respondents were also asked what length of tonic-clonic seizure they would accept. Twenty-one (24\%) accepted any tonic-clonic seizure; $30(35 \%)$ a seizure of at least 15 seconds and $34(39 \%)$ only accepted a seizure of at least 25 seconds. Psychiatric trainees were no more likely to demand seizures of at least 25 seconds than were non-trainees $\left(\chi^{2}\right.$ test: $P=0.56$ ).

\section{Opinions and impressions}

Eighty (93\%) doctors stated that they felt confident about the practical administration of ECT.

The questionnaire enquired whether opposition to the use of ECT had been met from nurses, social workers or family and friends. Fourteen (16\%) reported ever encountering opposition from nurses; $18(21 \%)$ from social workers and $52(60 \%)$ from family and friends.

Doctors were also asked whether they believed health care workers should be able to refuse to take part in the administration of ECT on moral grounds. Thirty-nine ( $45 \%$ ) felt they should be able to decline; $35(41 \%)$ that they should not, and $12(14 \%)$ did not know or had no opinion.

\section{Comment}

This study inquired into the training and routine practice of doctors administering ECT. The response rate was satisfactory from both psychiatric and general practice vocational trainees. Pippard (1992) personally observed the administration of ECT in 31 hospitals and reported on many aspects of treatment. However, it is possible that doctors make an extra effort to comply with guidelines when being observed by a senior doctor. By using an anonymous, selfcompletion format and surveying a large number of junior doctors, our study may provide a closer estimate of normal practice.

Almost all doctors had received some training on the theory and practice of ECT, although the few who had not are still of concern. Teaching methods varied from place to place, particularly for theoretical teaching. It is noteworthy that $21 \%$ did not report teaching at a practical session; $37 \%$ of doctors either had not or could not recall being issued with guidelines on the administration of ECT. That only $15 \%$ recalled a consultant psychiatrist being present while they were administering ECT, other than at an initial training session, is alarming, particularly in light of our findings on doctors' routine practice.
Only $24 \%$ timed seizures with a stopwatch or stopclock; $84 \%$ used a fixed or minimal stimulus, rather than the intermediate stimulus advised by Pippard (1992). Of respondents, 59\% accepted a seizure length of less than the 25 seconds recommended in College guidelines (Royal College of Psychiatrists, 1989). Despite this, almost all doctors were confident of their ability to administer ECT.

Bhatnagar (1987) suggested that opposition to the use of ECT from members of the multidisciplinary team may decrease its use. The proportion in our study encountering opposition from nurses or social workers was small (16\% and $21 \%$ respectively). However, all team members are in a position to influence patient opinion, and this proportion may still be important. The finding that $60 \%$ had met opposition to their administration of ECT from family or friends may reflect a continuing failure to inform the public of the benefits of ECT.

That $45 \%$ of respondents felt health care professionals should be able to decide not to take part in ECT on moral grounds is surprising. It seems to imply that doctors identify ECT as having the potential to cause moral concern. It may be that these doctors believe that health care workers should be able to decide not to take part in any treatment and not specifically ECT. This issue requires further exploration.

This study included doctors from a number of different training schemes. It demonstrates that there was no consistent means of providing training in the theory and practice of ECT. After an initial session it was uncommon for our respondents to have had their practical administration of ECT monitored by a consultant psychiatrist. While $93 \%$ of doctors were confident about their ability to administer ECT, most did not routinely comply with Pippard's recommendations and College guidelines on its administration. Current training, however provided, does not appear to be effective.

\section{References}

Bhatnagar, K. (1987) Decline in the use of ECT: the York study. Bulletin of the Royal College of Psychiatrists, 11, 303-304.

KendeLl, R. E. (1981) The present status of electroconvulsive therapy. British Journal of Psychiatry, 139, 265-283.

PIPPARD, J. (1988) ECT custom and practice. Psychiatric Bulletin, 12, 473-475.

- (1992)Audit of electroconvulsive treatment in two National Health Service regions. (1992) British Journal of Psychiatry, 160, 621-637.

Royal College of Psychiatrists (1989) The Practical Administration of Electroconvulsive Therapy (ECT). London: Gaskell (Royal College of Psychiatrists). 